\title{
El liderazgo visionario del papa Francisco sobre las personas en movimiento
}

\author{
Pope Francis's visionary leadership \\ on people on the move
}

Diego Carámbula*

ISSN IMPRESO 1870-7599 | ISSN RED CÓMPUTO 2448-7783 | 177-204

Amaya Valcárcel**

\section{Introducción}

A lo largo de su pontificado, el papa Francisco ha modelado y predicado a un Dios de justicia y misericordia. Su gran logro ha sido atraer la atención del mundo sobre los seres humanos más vulnerables y aquellos que se encuentran en situaciones difíciles. La defensa de los derechos de migrantes y refugiados se ha convertido en un tópico central. Asimismo, el papa Francisco ha hecho de las adversidades que enfrentan migrantes y refugiados en el mundo un punto clave no sólo en palabras, sino en acciones. Su mensaje para la Jornada Mundial de la Paz de 2018 abordó el tema «Migrantes y refugiados: hombres y mujeres que buscan la paz». Con su característico estilo directo, se preguntó «ipor qué tantos refugiados y migrantes?», recordó cómo varios años antes, el papa san Juan Pablo II había puntualizado en «el creciente número de personas desplazadas como una de las consecuencias de la interminable y horrible secuencia de guerras, conflictos, genocidios y limpiezas étnicas»» (papa Francisco, 2018, \#4). Reconoció también que los seres humanos tienen un deseo natural de buscar una vida mejor, y que la pobreza y la degradación del medio ambiente son factores que, de igual modo, fomentan la migración.

\footnotetext{
* Uruguayo/italiano. Coordinador regional para América del Sur de la Sección Migrantes y Refugiados, perteneciente al Dicasterio para el Servicio del Desarrollo Humano e Integral del Vaticano.

** Española. Abogada para el Alto Comisionado de Naciones Unidas para los Refugiados (ACNUR) en España y en el campo de refugiados de Kakuma, en el norte de Kenia. Correo-e: avalcarcel@migrants-refugees.org

Traducido del inglés por Georgia Aralú González Pérez y Carlos Omar Palacios Palacios.
} 
Este énfasis en la justicia social se enfoca profundamente en Cristo. No ignora en absoluto el trabajo o la teología de sus predecesores inmediatos, los papas san Juan Pablo II y Benedicto XVI, quienes hicieron importantes y duraderas contribuciones a la teología católica durante sus pontificados, en específico en su doctrina social. En efecto, diríamos que sentaron gran parte de los fundamentos teológicos para el trabajo posterior del papa Francisco. Por ejemplo, su mensaje en el Día Mundial de la Paz de 2018 sobre «Migrantes y refugiados: hombres y mujeres que buscan la paz» instaba a inspirarse «en las palabras de san Juan Pablo II: «Si el «sueños de un mundo en paz es compartido por todos, si la contribución de los refugiados y los migrantes es valorada adecuadamente, entonces la humanidad podrá convertirse cada vez más en una familia universal y nuestra tierra en una verdadera casa común» (papa Francisco, 2018, \#22).

En los últimos años, un sentido equivocado de autoconservación ha conducido a una obsesión por mantener a los migrantes alejados de las fronteras nacionales; esto ha cerrado los corazones y las mentes ante la realidad de las esperanzas, los temores y las aspiraciones de algunas de las personas más necesitadas del mundo. El papa Francisco sugiere que nosotros, que vivimos en la comodidad y la seguridad, debemos escuchar su historia y apreciar la imagen completa de su viaje. A lo largo de los años de su pontificado ha mantenido constantemente su compromiso y ha manifestado una visión clara y radical basada en un enfoque alternativo y más humano con respecto a los desafíos de la migración involuntaria.

Este artículo presenta y analiza el liderazgo visionario del papa Francisco y los principios que alimentan su agenda concreta para una mejor protección de los refugiados, los migrantes, las víctimas de la trata de personas, los desplazados internos y los desplazados climáticos, todos ellos en movimiento en busca de seguridad. Nuestro estudio comienza con la ahora famosa visita del papa a Lampedusa en julio de 2013 y la introducción del concepto de desorientación y la enseñanza resultante. Su visita a Lesbos en Grecia, tres años después, también ha sido fundamental en ese viaje. En seguida, nos detenemos en la nueva institución que creó con el propósito de dirigirla personalmente: la Sección Migrantes y Refugiados (M\&R, por sus siglas en inglés), vinculada al Dicasterio para el Servicio del Desarrollo Humano Integral. Demostramos cómo la visión del papa Francisco condujo a los 20 Puntos de Acción para los Pactos Globales de la Santa Sede en 2018. Profundizamos en la evolución del enfoque teológico que infunde este documento, en particular los cuatro conceptos en apariencia ordinarios pero radicales y esenciales dentro del enfoque evolutivo de la Santa Sede: acoger, 
proteger, promover e integrar. De manera complementaria, consideramos cómo se ha llegado a reconocer el mal de la trata de personas y la necesidad de esclarecer la difícil situación de los desplazados internos y los desplazados climáticos.

\section{Lampedusa, julio de 2013}

Inmigrantes muertos en el mar, en barcos que, de ser vehículos de esperanza, se volvieron vehículos de muerte. Así lo dicen los titulares. Cuando hace unas semanas escuché por vez primera esta tragedia y me di cuenta que esto sucede con demasiada frecuencia, la noticia regresa constantemente a mí como una espina dolorosa en mi corazón (...). ¿Alguno de nosotros ha llorado por estas personas que iban en la embarcación? ¿Por las madres jóvenes que llevaban a sus bebés? ¿Por esos hombres que buscaban un medio para mantener a sus familias? Somos una sociedad que ha olvidado cómo llorar, cómo sentir compasión — «sufrir con» otros: ila globalización de la indiferencia nos ha quitado la capacidad de llorar! (papa Francisco, 2013, \#1).

En julio de 2013, como primer viaje de su pontificado, el santo padre salió en barco a la isla de Lampedusa, frente a la costa sur de Sicilia. Esta isla italiana es un conocido lugar de desembarco para "los refugiados del mar», en su mayoría africanos, que intentan el peligroso viaje a través del Mediterráneo desde el norte de África hasta Europa.

El momento y el contexto de su visita fueron significativos. Fue después de la "Primavera Libia», y de la captura y el asesinato del expresidente libio, Muamar el Gadafi, en octubre de 2011. Libia estaba sumida en la violencia y la inestabilidad. Los africanos más pobres, atraídos por el trabajo disponible bajo la expansión económica de Gadafi, buscaban ahora en otra parte, en concreto al otro lado del Mediterráneo.

Durante su estancia en Lampedusa, el papa Francisco celebró una misa para conmemorar a los miles de migrantes que habían muerto al cruzar por el Mediterráneo. Adicionalmente, pronunció la ya famosa homilía donde explicó sentirse obligado a venir «para rezar y ofrecer una señal de mi cercanía, pero también para interpelar a nuestras conciencias y evitar que no se repita esta tragedia. iPor favor, que no se repita!» Después reflexionó sobre las dos primeras preguntas que Dios hace a la humanidad en las Sagradas Escrituras: 
«Adán, ¿dónde estás?» Esta es la primera pregunta que Dios hace al hombre después de su pecado. «Adán, ¿dónde estás?» Adán perdió su rumbo, su lugar en la creación porque pensó que podía ser poderoso, capaz de controlarlo todo, de ser Dios. Se perdió la armonía. El hombre se equivocó y este error se produce una y otra vez también en las relaciones con los demás. «El otro» ya no es un hermano o hermana al cual amar, sino simplemente alguien que perturba mi vida y mi comodidad. Dios hace una segunda pregunta: "Caín, ¿dónde está tu hermano?» La ilusión de ser poderoso, de ser tan grande como Dios, de ser incluso Dios mismo nos conduce a toda una serie completa de errores, a una cadena de muerte, ihasta el derramamiento de la sangre de un hermano! (papa Francisco, 2013, \#3).

El papa Francisco ha utilizado las narraciones de Adán y Caín como analogías en varias ocasiones, inclusive en su tratamiento de la ecología integral en la Carta Encíclica Laudato si' de 2015. Él interpreta estos pasajes como historias de desorientación humana, primeros signos de una tendencia en la humanidad a perder no sólo nuestro lugar dentro de la creación sino nuestra orientación como criaturas hacia un creador. En ese sentido, caer es desorientarse, desarraigarse, perder el rumbo (Rowlands, 2018).

«Cuántos de nosotros», se preguntó ante los migrantes en Lampedusa, «hemos perdido la dirección. Ya no estamos atentos al mundo en el que vivimos; no nos preocupamos; ino protegemos lo que Dios ha creado para todos, y terminamos siendo incapaces de cuidarnos unos a otros!» (papa Francisco, 2013, \#4). Para el santo padre, "cuando la humanidad en su conjunto pierde el rumbo, se producen tragedias como las que hemos presenciado». Lamentó cómo

hemos caído en la hipocresía del sacerdote y el levita que Jesús describió en la parábola del buen samaritano: vemos a nuestro hermano medio muerto al lado del camino, y quizá nos decimos a nosotros mismos: «ipobre alma...!» y luego seguimos nuestro camino. No es nuestra responsabilidad y con eso nos sentimos tranquilos, aliviados. La cultura de la comodidad, que nos hace pensar sólo en nosotros mismos, nos hace insensibles a los gritos de los demás, nos hace vivir en burbujas de jabón que, por muy bonitas que sean, son insustanciales; nos ofrecen una ilusión fugaz y vacía que da lugar a la indiferencia hacia los demás; es más, incluso nos conduce a la globalización de la indiferencia. En este mundo globalizado, hemos caído en la indiferencia globalizada. Nos hemos acostumbrado al sufrimiento de los demás: ino me afecta; no me concierne; no es asunto mío! (papa Francisco, 2018, \#6). 
La reflexión sobre Lampedusa revela la manera en que la respuesta del papa a una tragedia humana concreta comenzó como un gesto sincero arraigado en los principios bíblicos y en la doctrina social católica, y evolucionó a medida que absorbía las experiencias vividas por otros con fundamento en una gran variedad de fuentes. En Evangelii Gaudium, el papa Francisco compartiría más tarde que «los migrantes representan un desafío particular para mí, ya que soy el pastor de una Iglesia sin fronteras, una Iglesia que se considera madre de todos. Por esta razón, exhorto a los países a una apertura generosa» (papa Francisco, 2013, \#210). La enseñanza judeocristiana de que la tierra no es el destino final de la humanidad significa que la fe católica es, en su esencia, migratoria — todos somos migrantes, «estamos de paso».

Una de las contribuciones únicas del papa Francisco para abordar la cuestión de la migración ha sido su insistencia en realizar «viajes personales» con migrantes y refugiados, o "gestos de cercanía»: ver, escuchar, acoger, proteger, asistir e integrar, buscar soluciones a largo plazo. Se basa en las propias palabras de Jesús: "Haced a los demás todo lo que queráis que os hagan a vosotros», como se evoca en Lucas 6:31. En su exhortación apostólica, Evangelii Gaudium, el santo padre explica dicho enfoque:

Las realidades son más grandes que las ideas (...). El principio de una realidad, de una palabra ya hecha carne y que se esfuerza constantemente por encarnarse de nuevo es esencial/fundamental para la evangelización (...) este principio nos impulsa a poner en práctica la palabra para realizar obras de justicia y caridad que vuelvan a esta palabra fructífera. No poner en práctica la palabra, no hacerla realidad es construir sobre arena, permanecer en el mundo de las puras ideas (papa Francisco, 2013, \#175).

Ya en el discurso de Lampedusa, nos percatamos cómo el papa Francisco yuxtapone un relato de la desorientación de los asentados con relación a la orientación de los desplazados. Lo anterior constituye el primer pilar clave de su enfoque sobre la migración involuntaria. Con la finalidad de identificar por qué está fallando la respuesta predominante, debemos observar nuestra propia desorientación. El papa Francisco sitúa esta desorientación en aspectos de la sociedad contemporánea cuando enfatiza en la cultura del exceso y el egocentrismo que engendra indiferencia hacia los demás. En cierto modo, nuestras creencias culturales transitorias generan indiferencia hacia las personas verdaderamente transitorias. Así, 
al crear la transitoriedad de lo establecido, la globalización también produce, como subproducto, la globalización de la indiferencia (Rowlands, 2018).

Es importante subrayar que este pontificado coincide con el crecimiento del número mundial de desplazados a escala mundial hasta sus niveles más altos desde el final de la Segunda Guerra Mundial, en lo que muchos han denominado «crisis de refugiados». El término es realmente problemático. En primer lugar, implica que los desplazados que buscan refugio son la causa de su propia huida. Esto simplemente no es el caso: Laudato si' destaca la magnitud de los migrantes inducidos por el clima y la pobreza, y aquellos que huyen de la guerra y la miseria. Curiosamente, el papa Francisco ha cambiado de modo brillante el énfasis al insistir en que debemos reconocer esta crisis como una crisis de solidaridad ("Nuestra falta de respuesta a estas tragedias que afectan a nuestros hermanos y hermanas apunta a la pérdida de ese sentido de responsabilidad por nuestros semejantes en el que se basa toda sociedad civil», papa Francisco, 2013, párrafo 25). Su discurso de Lampedusa sembró las semillas de su enseñanza sobre la "globalización de la indiferencia», es decir, la insensibilidad con la que los individuos y las comunidades tratan a las personas pobres, desesperadas y marginadas. ¿Qué prescribe? Comienza con nosotros - parafraseando su discurso de Lampedusa-, nosotros que «nos hemos acostumbrado al sufrimiento de los demás», nosotros que "sólo pensamos en nosotros mismos», nosotros que somos «insensibles a los gritos de los demás». La esencia de esta enseñanza, creemos, nos llama a todos a reflexionar sobre nosotros mismos y a experimentar una metanoia, un giro que exija respuestas positivas y humanas ante tales movimientos desesperados de personas. Es una conversión del corazón.

\section{Lesbos, abril de 2016}

Tras los grandes flujos de refugiados, principalmente sirios y afganos, hacia Europa durante 2015 y 2016, el papa Francisco visitó el campo de refugiados de Moria en la isla griega de Lesbos el 16 de abril de 2016. Les dijo:

Hoy he querido estar con ustedes. Quiero decirles que no están solos. En estas semanas y meses han soportado mucho sufrimiento en su búsqueda de una vida mejor. Muchos se sintieron obligados a huir de situaciones de conflicto y persecución, sobre todo por el bienestar de sus hijos, de sus pequeños. Han hecho grandes sacrificios 
por sus familias. Conocen el dolor de haber dejado atrás todo lo que les es querido y - lo que quizá sea más difícil — no saber lo que les depara el futuro. Muchos otros como ustedes están en campamentos o pueblos, aguardando, con la esperanza de construir una nueva vida en este continente (papa Francisco, 2016, \#1).

Esta vez adoptó un enfoque ecuménico, al aparecer junto con su beatitud Jerónimo, arzobispo de Atenas y de toda Grecia, y su santidad Bartolomé, Patriarca Ecuménico de Constantinopla. Su intención ha sido encender un movimiento de conciencia mundial para cambiar el trágico curso de estos acontecimientos y alertar a quienes tienen en sus manos el destino de las naciones. A los refugiados y migrantes ahí reunidos les expresó:

He venido aquí con mis hermanos, el patriarca Bartolomé y el arzobispo Jerónimo, simplemente para estar con ustedes y escuchar sus historias. Hemos venido a llamar la atención del mundo sobre esta grave crisis humanitaria y a pedir que se resuelva. Como personas de fe, deseamos unir nuestras voces para hablar en su nombre. Esperamos que el mundo preste atención a estas escenas de trágica y desesperada necesidad, y que respondan de una manera digna de nuestra humanidad común (papa Francisco, 2016, \#2).

Al igual que en su visita a Lampedusa, la evolución del pensamiento del papa Francisco sobre los migrantes, los refugiados y la trata de personas surge de encuentros concretos. Aquí, se enfrenta claramente al gran riesgo de la indiferencia y de la explotación; no obstante, destaca asimismo la amabilidad y la bondad poco reconocidas que muchas personas muestran cuando se encuentran con migrantes en situación desesperada. Como si este encuentro fuera un tesoro escondido, excava más allá y emerge con la idea de la «cultura del encuentro»:

Todos sabemos por experiencia lo fácil que es para algunos ignorar el sufrimiento de otras personas e incluso aprovechar su vulnerabilidad. Aunque también sabemos que estas crisis pueden sacar lo mejor de nosotros. Lo han visto entre ustedes y entre el pueblo griego, que ha respondido generosamente a sus necesidades en medio de sus propias dificultades. También lo han visto en numerosas personas, especialmente jóvenes de toda Europa y del mundo, que han venido a ayudarlos. Sí, iqueda mucho por hacer! Pero demos gracias a Dios porque en nuestro sufrimiento nunca nos deja solos. Siempre hay alguien que puede acercarse y ayudarnos (papa Francisco, 2016, \#3). 
El campamento de Moria fue incendiado en 2020 por algunos de los propios refugiados residentes en un intento acuciante por atraer la atención de la comunidad internacional sobre sus horrendas condiciones de vida y sus desesperadas realidades. Esto, junto con muchos otros, es todavía hoy una señal de la falta de capacidad global para gestionar la migración. En su discurso al Primer Ministro, a las autoridades griegas y a la comunidad católica en Grecia, el papa Francisco planteó la cuestión crítica de abordar las causas de raíz como solución a la migración:

Para estar verdaderamente unidos con quienes se ven obligados a huir de sus países, debemos eliminar las causas de esta dramática situación: no basta con limitarnos a responder a las emergencias a medida que surgen. Por el contrario, debemos alentar los esfuerzos políticos que son de mayor alcance y multilaterales. Es necesario, sobre todo, construir la paz ahí donde la guerra ha traído destrucción y muerte, y detener la propagación de este flagelo. Deben realizarse esfuerzos decididos a fin de contrarrestar el comercio y tráfico de armas, así como las maquinaciones a menudo asociadas con ellas; a quienes cometen actos de odio y violencia se les deben negar todos los medios de apoyo. Se debe promover incansablemente la cooperación entre naciones, organizaciones internacionales y agencias humanitarias, y se debe ayudar a aquellos al frente, no mantenerlos a distancia (papa Francisco, 2016, \#7).

\section{Respuesta a Lampedusa y Lesbos: el establecimiento de la Sección Migrantes y Refugiados}

Inmediatamente después de su visita a Lesbos, el santo padre creó la Sección Migrantes y Refugiados (M\&R), vinculado al Dicasterio para el Servicio del Desarrollo Humano Integral. Se estableció para ser «competente en particular en temas relacionados con los migrantes, los necesitados, los enfermos, los excluidos y marginados, los presos y los desempleados, además de las víctimas de conflictos armados, desastres naturales y todas las formas de esclavitud y tortura» (M\&R, 2017).

Dirigida personalmente por el papa Francisco, la Sección M\&R se orienta en específico a lograr su visión: 
En Lampedusa y Lesbos, principales puntos de tránsito en Italia y Grecia, el papa Francisco lloró con los migrantes y refugiados congregados allí. En el avión de regreso de Lesbos, llevó a algunas familias de refugiados sirios a vivir en el Vaticano. «Cuando curamos las heridas de los refugiados, las personas desplazadas y las víctimas de la trata», dijo, «estamos practicando el mandamiento del amor que Jesús nos dejó (...). Su carne es la de Cristo» (24 de mayo de 2013). Lo que el Papa enseña y hace él mismo, quiere que la Sección M\&R ayude a otros a decir y hacer en todo el mundo (M\&R, 2017).

En consecuencia, la misión de la Sección M\&R es ayudar a la Iglesia (esto es, a los obispos, los fieles, el clero, las organizaciones eclesiásticas) y a toda persona de buena voluntad, a «acompañar» a los que parten y huyen, a los que se encuentran en tránsito o esperan, a los que llegan y buscan integrarse, y a los que regresan.

Uno de los principales logros de la Sección M\&R ha sido ayudar a nutrir y hacer crecer las semillas plantadas por el papa en su intervención en Lampedusa. El departamento ha estado comprometido con ayudar a desarrollar aún más la base teológica e intelectual para un enfoque católico más vigoroso con respecto al desplazamiento humano. En 2020, se publicó una voluminosa colección de enseñanzas del papa Francisco sobre la atención pastoral hacia los migrantes, refugiados y víctimas de la trata de personas, de acuerdo con el título en inglés Lights on the ways of hope.

En un nivel más práctico, la Sección M\&R encabezó el esfuerzo que condujo a los 20 Puntos de Acción del Vaticano para los Pactos Globales sobre Migración y Refugiados, y las Orientaciones Pastorales sobre la Trata de Personas, que se analizan más adelante en este documento, y también las relativas a las personas desplazadas internas y, más recientemente, a la crisis climática y los desplazamientos.

El establecimiento del dicasterio y la ubicación de la Sección M\&R dentro de él y bajo el liderazgo directo del papa demuestran claramente su continuo compromiso para aliviar la difícil situación de los refugiados y los migrantes. Esta institucionalización puede verse como parte de un proceso de interiorización del propio Vaticano de las enseñanzas del papa sobre la crisis de solidaridad, y un giro hacia la acción como resultado de una mayor compasión y comprensión de los problemas migratorios.

Dicha oficina se vincula al trabajo mundial de la Iglesia con las personas desplazadas por la fuerza, y está firmemente convencida de que la llamada «crisis 
migratoria global» no se entiende mediante una respuesta global sino local, a través de la peculiaridad de cada contexto y de las personas que forman parte de la aludida respuesta.

\section{Desarrollo y logro de la visión}

Al igual que sus predecesores, el papa Francisco se ha basado en elementos centrales de la fe cristiana y la doctrina social católica al desarrollar una visión clara y radical de un enfoque alternativo y más humano en torno a los desafíos de la migración involuntaria. La publicación de la Sección M\&R de 2020, Lights on the ways of hope, confirma las enormes contribuciones doctrinales, teológicas y políticas que este papa ha realizado.

Desde el inicio de su pontificado, el papa Francisco ha animado con sus palabras y acciones a la Iglesia católica a seguir «acompañando» a todas las personas que se ven obligadas a huir de sus hogares y de su tierra natal. En febrero de 2017, el santo padre se dirigió al Foro Internacional sobre Migración y Paz reunido en Roma. Declaró que la respuesta a los desafíos de la migración contemporánea debe ser compartida entre la comunidad política, la sociedad civil y la Iglesia, y debe articularse en términos de cuatro acciones interrelacionadas: acoger, proteger, promover e integrar (papa Francisco, 2017).

En el actual escenario migratorio, «acoger» significa mejorar los canales legales y seguros para los migrantes y refugiados. El santo padre, en su mensaje para la Jornada Mundial del Migrante 2018, traduce tal mejora en «ofrecer opciones más amplias para que los migrantes y refugiados ingresen a los países de destino de manera segura y legal. Esto exige un compromiso para aumentar y simplificar el proceso de concesión de visas humanitarias y de reunificación familiar» (papa Francisco, 2018, \#5). Los migrantes y refugiados que llaman a las puertas de países, donde pueden encontrar protección, representan una oportunidad concreta para ejercer la justicia, practicar la solidaridad y construir la fraternidad.

En cuanto a «proteger», así lo explicó en su discurso a los Directores Nacionales para la Pastoral de los Migrantes el 22 de septiembre de 2017. Se trata de "ofrecer información confiable y verificada a los migrantes y refugiados antes de su partida, defender sus derechos básicos independientemente de su estatus legal, y velar por los más vulnerables: los niños pequeños» (papa Francisco, 2017, \#6). La especial preocupación del santo padre por estos últimos lo llevó a dedicar a 
los niños migrantes y refugiados el Mensaje de 2017 para la Jornada Mundial de los Migrantes y Refugiados.

La tercera acción, "promover», tiene que ver con el desarrollo humano integral, la realización de las aspiraciones naturales de cada persona en todas las dimensiones de la vida humana. Hay muchas posibilidades de promover a los migrantes, a los refugiados y a las comunidades de acogida. Como lo declaró en su discurso a los participantes en el Foro Internacional sobre Migración y Paz el 21 de febrero de 2017:

El desarrollo (...) es un derecho innegable de todo ser humano. Como tal, debe garantizarse al asegurar las condiciones necesarias para su ejercicio, tanto en el contexto individual como social, proporcionando un acceso equitativo a los bienes fundamentales para todas las personas y ofreciendo la posibilidad de elección y crecimiento (papa Francisco, 2017, \#7).

«Integrar», según el papa Francisco en su mensaje para la 104ª Jornada Mundial de los Migrantes y Refugiados 2018, «se refiere a las oportunidades de enriquecimiento intercultural que brinda la presencia de migrantes y refugiados» (papa Francisco, 2018, \#8). La integración no es sinónimo de asimilación. Es un proceso bidireccional de aprendizaje que respeta y valora la cultura del otro con miras a construir una sociedad rica, cohesionada e intercultural. En ese mensaje, el santo padre reitera "la necesidad de fomentar una cultura de encuentro de todas las formas posibles, al aumentar las oportunidades de intercambio intercultural, documentar y difundir las mejores prácticas de integración, y desarrollar programas que preparen a las comunidades locales para estos procesos de integración» (papa Francisco, 2018, \#8).

La Sección M\&R, bajo el liderazgo directo del papa Francisco, posteriormente elaboró y publicó un conjunto de 20 Puntos de Acción para los Pactos Globales sobre Migración y Refugiados (20 Puntos de Acción) como una contribución a la planeación, negociación y adopción de los Pactos Globales sobre Migrantes y Refugiados a finales de 2018. Estas consultas se realizaron al escuchar las Conferencias Episcopales y a las ONG católicas que trabajan en esa área, las cuales incluyeron una profunda reflexión acerca de las mejores prácticas de la Iglesia que se han desarrollado a lo largo de los años.

Los 20 Puntos de Acción abogan por medidas efectivas y probadas que, en conjunto, constituyan una respuesta integral a los desafíos actuales. De acuerdo 
con la enseñanza del papa Francisco, los puntos se agrupan en cuatro apartados: acoger, proteger, promover e integrar. Cada uno es un verbo activo y una llamada a la acción. A partir de lo que es viable en el presente, su objetivo final es la construcción de una casa común inclusiva y sostenible para todos.

Se pretende que estos puntos de acción «proporcionen una orientación de bienvenida a los responsables políticos y a aquellos que se preocupen por mejorar la situación de los migrantes, los refugiados, los solicitantes de asilo y los desplazados internos, en especial los más vulnerables» (Sección M\&R, 2018). También confirman el compromiso del Vaticano de hacer una contribución significativa a los esfuerzos internacionales para gestionar todas las dimensiones de la migración internacional. En 2018, esto se refería a los Pactos Mundiales de las Naciones Unidas sobre Migración y Refugiados. Los datos empíricos muestran que la migración es cada vez más mixta, lo que dificulta mantener una distinción clara entre migrantes y refugiados. A menudo sus necesidades son muy similares, casi idénticas. En consecuencia, la planeación y la negociación deben pugnar por alcanzar la mayor armonía posible entre los dos pactos mundiales. Además, ambos deben tener un impacto real en la vida de las personas y, por ende, incluir metas y objetivos a cumplir, así como mecanismos de información.

Paralelamente, la Sección M\&R elaboró un documento denominado 20 Puntos de Acción Pastoral para uso de diócesis católicas, parroquias y congregaciones religiosas, organizaciones católicas y de la sociedad civil, escuelas y grupos que atienden a migrantes y refugiados. Estos 20 Puntos de Acción Pastoral sirven de igual modo como una hoja de ruta teológicamente fundamentada, pero práctica para responder en el nivel individual, comunitario, nacional e internacional expresamente «con la esperanza de fomentar una solidaridad más efectiva con los migrantes y refugiados» (Sección M\&R, 2018). Sin embargo, no deberán considerarse como la suma de la enseñanza de la Iglesia sobre los migrantes y los refugiados; el documento deja claro que no es exhaustivo.

Los 20 Puntos de Acción Pastoral se basan en los cuatro conceptos o acciones ya mencionados, que sustentan la visión del papa Francisco acerca de un enfoque mejorado y más compasivo sobre el desplazamiento humano, además brindan claridad en torno a la posición de la Iglesia. Con fundamento en estos conceptos de febrero de 2017, el santo padre agrupa sus recomendaciones para los pactos mundiales de 2018 de la siguiente manera: 
"Acogida» exige ampliar las vías legales de entrada y dejar de empujar a los migrantes y desplazados hacia países donde enfrentan persecución y violencia. Exige también equilibrar nuestra preocupación tanto por la seguridad nacional como por los derechos humanos fundamentales. Las Sagradas Escrituras nos recuerdan: «No olvides dar hospitalidad a los extranjeros, porque al hacerlo algunos han dado hospitalidad a los ángeles sin saberlo».

«Proteger» tiene que ver con nuestro deber de reconocer y defender la inviolable dignidad de quienes huyen de peligros reales en busca de asilo y seguridad, y evitar que sean explotados. Pienso en particular en las mujeres y los niños en situaciones que los exponen a riesgos y abusos que pueden incluso llegar a la esclavitud. Dios no discrimina: «El Señor cuida al extranjero y sostiene al huérfano y a la viuda».

«Promover» implica apoyar el desarrollo humano integral de los migrantes y los refugiados. Entre los diversos medios posibles para hacerlo, destacaría la importancia de garantizar el acceso de niños y jóvenes en todos los niveles de educación. Esto les permitirá no sólo cultivar y darse cuenta de su potencial, sino prepararlos mejor para el encuentro con los demás y fomentar un espíritu de diálogo en lugar de rechazo o confrontación. La Biblia enseña que Dios «ama al extranjero que reside entre ustedes, le da comida y vestido. Y deberán amar a los extranjeros, porque ustedes mismos fueron extranjeros en Egipto».

«Integrar», por último, significa permitir a los refugiados y a los migrantes participar plenamente en la vida de la sociedad que los acoge, como parte de un proceso de enriquecimiento mutuo y cooperación fructífera al servicio del desarrollo humano integral de la comunidad local. San Pablo lo expresa con estas palabras: «Ya no son extranjeros ni forasteros, sino conciudadanos del pueblo de Dios» (papa Francisco, 2018, \#14-18).

El cuadernillo de los 20 Puntos de Acción aborda estas cuatro acciones y amplía la forma en que se pueden implementar.

Acoger: incremento de rutas seguras y legales para migrantes y refugiados

El concepto o acción de «acoger» ha adquirido un significado radicalmente nuevo en las enseñanzas del papa Francisco:

Acoger significa, sobre todo, ofrecer más opciones para que los migrantes y refugiados ingresen a los países de destino de manera segura y legal. Esto exige un compromiso 
concreto para aumentar y simplificar el proceso de concesión de visas humanitarias y de reunificación familiar. Al mismo tiempo, espero que un mayor número de países adopten programas de patrocinio privado y comunitario, y que abran corredores humanitarios para los refugiados particularmente vulnerables. Asimismo, deberían otorgarse visas especiales temporales a las personas que huyen de conflictos en países vecinos. Las expulsiones colectivas y arbitrarias de migrantes y refugiados no son soluciones adecuadas, en particular cuando las personas son devueltas a países que no pueden garantizar el respeto de la dignidad humana y los derechos fundamentales. Una vez más, quiero subrayar la importancia de ofrecer a los migrantes y refugiados un alojamiento inicial adecuado y digno (papa Francisco, 2018, \#5).

La enseñanza del papa sobre la acogida de migrantes y refugiados debe considerarse en el contexto de un mundo donde la ausencia de medios para viajar de manera segura y legal ha provocado un auge en el tráfico de seres humanos, aparte de exponer a los refugiados y migrantes al abuso y a la explotación, así como al peligro de caer en manos de traficantes y otros delincuentes. Los seres humanos arriesgan sus vidas al embarcarse en botes no aptos para navegar los océanos Mediterráneo, Índico y Pacífico; al trepar las vallas de las fronteras terrestres exteriores de la Unión Europea o en el arriesgado Triángulo Norte hacia México y luego hacia Estados Unidos. Para la mayoría de las personas que necesitan protección, ésta es la única alternativa de escapar de la guerra, la pobreza, un panorama ambiental hostil y cambiante o la persecución.

De acuerdo con la visión del papa Francisco, en los 20 Puntos de Acción del uno al tercero cubren el aspecto «acoger» como respuesta a la migración. Éstos incluyen:

a) La extensión de «visas humanitarias» o, si ya existen, su expansión como una prioridad de política nacional.

b) El uso más amplio de visas de estudiantes.

c) La adopción de programas de «corredores humanitarios» que permitan la entrada legal con una visa humanitaria a personas en situaciones particularmente vulnerables.

d) Una legislación que posibilite la integración local a través del patrocinio comunitario y privado de ciudadanos, comunidades y organizaciones.

e) La adopción de políticas de reasentamiento para refugiados o, si ya están presentes en el marco legal, el aumento del número de refugiados reasentados 
en una escala que permita satisfacer las necesidades anuales de reasentamiento identificadas por el ACNUR.

f) La concesión de visas de reunificación familiar o, si ya están disponibles, la expansión del número de visas emitidas a miembros de la familia extendida, incluidos abuelos, hermanos y nietos; y la concesión inmediata del estatuto de protección temporal a las personas obligadas a huir del conflicto armado, la persecución o la violencia generalizada.

El tercer punto reconoce la validez de las preocupaciones por la seguridad nacional y pide un equilibrio correcto entre el valor de la seguridad de cada persona - arraigado en un profundo respeto por los derechos inalienables de los migrantes, solicitantes de asilo y refugiados - y las preocupaciones sobre seguridad nacional.

Proteger: defensa de los derechos y dignidad de los migrantes y refugiados

El papa Francisco ha hablado de su visión acerca de la protección en los siguientes términos: "Proteger implica ofrecer información confiable y verificada a los migrantes y refugiados antes de su partida, defender sus derechos básicos independientemente de su estatus legal y velar por los más vulnerables, los niños pequeños» (papa Francisco, 2017, \#9).

Bajo este epígrafe de "proteger» se identifican siete puntos, basados en una comprensión holística de la naturaleza multidimensional de la vida de la persona humana, y en un enfoque integrado como la mejor manera de detectar y superar estereotipos dañinos; de manera que en lugar de estigmatizar a una persona se tomen en cuenta todas sus dimensiones. Las recomendaciones se dirigen a legisladores y funcionarios gubernamentales:

1. Los países de origen deben tomar medidas para asistir y apoyar a quienes buscan emigrar, por ejemplo, ofrecer información confiable antes de su partida.

2. Los países de llegada deben proteger a los inmigrantes para evitar la explotación, el trabajo forzoso y la trata de personas, toda vez que prohíban a los empleadores retener los documentos de los trabajadores y establezcan un salario mínimo aplicable a ellos.

3. Los migrantes, los solicitantes de asilo y los refugiados deben estar facultados para aprovechar sus habilidades y competencias, encauzadas a mejorar su propio bienestary la prosperidad de sus comunidades, es decir, asegurar la libertad 
de circulación en el país y el permiso para regresar después de trabajar en el extranjero o en sus países de origen.

4. Los menores no acompañados y aquellos separados de sus familias deben ser tratados de conformidad con la Convención Internacional sobre los Derechos del Niño, por ejemplo, al buscar soluciones alternativas a la detención de migrantes menores de edad que ingresan a un país sin autorización.

5. Todos los migrantes menores de edad deben ser protegidos de conformidad con la Convención Internacional sobre los Derechos del Niño a través del registro obligatorio de todos los nacimientos, al garantizar que los migrantes menores de edad no sean irregulares cuando lleguen a la edad adulta y puedan continuar su educación.

6. Debe asegurarse el acceso a la educación a todos los migrantes menores de edad, solicitantes de asilo y refugiados en igualdad de condiciones que los ciudadanos e independientemente de su estatus legal.

7. El acceso a la seguridad social, incluida la asistencia sanitaria, debe proporcionarse a todos los migrantes, solicitantes de asiloy refugiados, además deben tener acceso a los planes nacionales de pensiones y la posibilidad de transferir las prestaciones de sus países de origen.

8. Los migrantes tienen derecho a la protección contra la apatridia y la a-nacionalidad de conformidad con convenciones internacionales.

Promover: fomento del desarrollo humano integral de los migrantes y refugiados

Si todo ser humano posee el derecho a desarrollarse, eso contempla a los más vulnerables, como los migrantes y los refugiados, quienes también debieran tener la oportunidad de cumplir sus aspiraciones naturales en cualquier dimensión de la vida humana. La promoción del desarrollo humano integral hace referencia a los Objetivos de Desarrollo Sostenible 2030 y a su principio de «no dejar a nadie atrás», hace una exhortación a la comunidad internacional para incluir a los refugiados, solicitantes de asilo y trabajadores migrantes en sus planes de desarrollo.

Existen cinco puntos que abordan el concepto o la acción de «promover» $\mathrm{y}$ se dirigen a legisladores y a funcionarios del Estado; todavía más, trascienden la «protección», por ejemplo:

1. Las competencias de los migrantes, los solicitantes de asilo y los refugiados deben valorarse y desarrollarse en los países de llegada, al garantizar la igualdad 
de acceso a la enseñanza superior, cursos de especialización, aprendizajes y pasantías, y al validar las cualificaciones obtenidas en otros lugares.

2. Deben emprenderse medidas que faciliten la inclusión de los migrantes, los solicitantes de asilo y los refugiados dentro de comunidades locales al reconocer sus cualificaciones, su derecho al trabajo, su libertad de movimiento y su derecho a elegir dónde vivir; asimismo, al facilitar información en sus lenguas de origen. Las barreras lingüísticas deben superarse mediante cursos de idiomas.

3. Los derechos de la familia, en particular la reunificación, deben respetarse y promoverse en un sentido holístico.

4. Deben tomarse acciones especiales para proteger a los más vulnerables aun al interior de este mismo grupo, como los menores y las personas con necesidades especiales.

5. Debe proveerse más apoyo internacional al desarrollo y a la ayuda humanitario a países receptores, con la finalidad de que satisfagan las necesidades de las poblaciones recién llegadas y residentes.

6. El derecho a la libertad religiosa —en términos de creencias y de prácticas - debe asegurarse a todos los migrantes, solicitantes de asilo y refugiados, independientemente de su condición jurídica.

Integrar: mayor participación de migrantes y refugiados para el enriquecimiento de comunidades locales

Una integración real requiere un nuevo tipo de sociedad que se eleve por encima de las suposiciones, a menudo tácitas, en torno a la hegemonía de uno u otro grupo racial o cultural. Ésta es radical, se centra en la persona e integra en sí misma diferentes vertientes de la doctrina social de la Iglesia al servicio de la solución de un problema humano. Poco después de su visita a Lampedusa, el papa Francisco se dirigió al Parlamento Europeo el 25 de noviembre de 2014: «Europa podrá hacer frente a los problemas asociados con la inmigración sólo si es capaz de afirmar claramente su propia identidad cultural y promulgar una legislación adecuada para proteger los derechos de los ciudadanos europeos, y garantizar la aceptación de los inmigrantes» (papa Francisco, 2014, \#32). Hizo especial énfasis acerca de dirigir una mirada contemplativa de fe a nuestro alrededor y ver a Dios entre nosotros:

Cuando dirigimos esa mirada hacia los migrantes y refugiados, descubrimos que no llegan con las manos vacías. Aportan su valor, habilidades, energía y aspiraciones, 
así como los tesoros de sus propias culturas; y de esta manera, enriquecen la vida de las naciones que los acogen. También llegamos a ver la creatividad, la tenacidad y el espíritu de sacrificio de las innumerables personas, familias y comunidades de todo el mundo que abren sus puertas y sus corazones a los migrantes y refugiados, incluso allí donde los recursos son escasos (papa Francisco, 2018, \#11).

Este título de los 20 Puntos de Acción retoma esa perspectiva, pues argumenta que los migrantes, los solicitantes de asilo y los refugiados brindan además de oportunidades de crecimiento para las comunidades locales y los recién llegados, un enriquecimiento cultural mutuo. Se sugieren tres medidas:

1. Fomentar un proceso de integración bidireccional que reconozca y valore las riquezas de ambas culturas, esto es, el reconocimiento de la ciudadanía por nacimiento y la rápida concesión de la nacionalidad a todos los refugiados, independientemente de los requisitos financieros o conocimientos lingüísticos.

2. Desarrollar y promover «una narrativa positiva de solidaridad hacia los migrantes, los solicitantes de asilo y los refugiados», por ejemplo, financiando proyectos de intercambio intercultural y apoyando programas de integración en las comunidades locales.

3. Garantizar que los migrantes que regresan cuenten con las condiciones adecuadas para reintegrarse en sus países de origen, por ejemplo, brindar un mayor apoyo al desarrollo de la infraestructura en los países de retorno, validar cualificaciones educativas y profesionales obtenidas en el extranjero, y fomentar la rápida reintegración de los trabajadores en sus países de origen.

Durante siglos, las personas desplazadas han recibido la asistencia y la atención pastoral especial de la Iglesia católica. Hoy, ante el mayor movimiento de personas desplazadas que se recuerde recientemente, la Iglesia se siente obligada a continuar esta labor de solidaridad con ellas y en cooperación con la comunidad internacional. La visión del papa Francisco sigue la doctrina católica sobre los derechos humanos a la vez que plantea un problema contemporáneo. Los 20 Puntos de Acción giran en torno a las enseñanzas de justicia social que él ha desarrollado desde que vio, de primera mano, la miseria en Lampedusa. 


\section{Reconocimiento de los males de la trata de personas}

Una clara evolución en el enfoque del santo padre sobre la migración es su reconocimiento de los males del fenómeno de la trata de personas y la necesidad de afrontarlo cuando se trata de la migración. Los migrantes son muy vulnerables a la trata de personas, dado que huyen en condiciones precarias; con frecuencia arriesgan sus vidas al intentar ingresar a un país de destino y correr el riesgo de ser deportados. En 2014 describió la trata de personas como «una herida abierta en el cuerpo de la sociedad contemporánea, un flagelo sobre el cuerpo de Cristo» (papa Francisco, 2014, \#2). El 29 de julio de 2018 enfatizó ante una plaza de San Pedro llena, que «las rutas de la migración a menudo son utilizadas por traficantes y explotadores para reclutar nuevas víctimas» (papa Francisco, 2018, \#9).

Adicionalmente, reconoció algo más profundo visible en la Exhortación Apostólica Evangelii Gaudium. Habló de una cultura de «usar y tirar», por la cual el ser humano es visto como un «bien de consumo» que puede usarse y desecharse (papa Francisco, 2013, \#53). En esta exhortación se refirió directamente a la trata de personas:

Siempre me ha angustiado la suerte de quienes son víctimas de diversos tipos de trata de personas. Cómo desearía que todos escucháramos el grito de Dios: «Dónde está tu hermano?» (Génesis 4:9). ¿Dónde está tu hermano o hermana que está esclavizado? ¿Dónde está el hermano y la hermana a los que matas todos los días en almacenes clandestinos, en redes de prostitución, en los niños utilizados para la mendicidad, en la explotación del trabajo indocumentado? No miremos para otro lado. La complicidad es mayor de lo que pensamos. iEl problema es de todos! Esta infame red delictiva está ahora bien implantada en nuestras ciudades, y muchas personas tienen las manos manchadas de sangre derivado de su cómoda y silenciosa complicidad (papa Francisco, 2013, \#211).

El santo padre se ha convertido en la voz de los que no tienen voz, de los que se vuelven una mercancía, un producto que se desplaza de un país a otro (Campana y Varese, 2015). Éstos se encuentran entre los más deshumanizados y descartados del mundo moderno y del mundo en sí. La trata de personas, afirma, es un «flagelo atroz» (papa Francisco, 2017, \#2), una «plaga aberrante» (papa Francisco, 30 de julio de 2017, \# 6) y una «herida abierta en el cuerpo de la sociedad 
contemporánea» (papa Francisco, 2014, \#2). A principios de 2015, dedicó su Mensaje Anual para la Jornada Mundial de la Paz a la trata de personas, destacó que «nos enfrentamos a un fenómeno global que excede las competencias de cualquier comunidad o país», y pidió «una movilización comparable en tamaño a la del fenómeno en sí» (papa Francisco, 2015, \#6). En 2016 instó a erradicar la trata y el tráfico de personas, consideradas éstas como nuevas formas de esclavitud, además como crímenes de lesa humanidad que deben ser regulados por la legislación local e internacional (cfr. papa Francisco, 2016).

Dos de las tres cartas encíclicas escritas por el papa Francisco hasta la fecha (Laudato si', 24 de mayo de 2015 y Fratelli tutti, 3 de octubre de 2020) consideran la trata de personas. Puede resultar sorprendente para algunos saber que en Laudato si', dentro del enfoque sobre el respeto al mundo natural, hace referencia a la indiferencia ante la trata de personas y a otros aspectos como la pobreza. La suya es una visión holística de la creación de Dios. Advierte cómo el cuidado de la naturaleza no puede existir separado del cuidado de la persona humana: «Es claramente incoherente combatir el tráfico de especies en peligro de extinción y, al mismo tiempo, permanecer completamente indiferentes a la trata de personas, despreocuparse de los pobres o emprender la destrucción de otro ser humano considerado indeseable» (papa Francisco, 2015, \#91).

Habría sido sorprendente no haber incluido alguna referencia a la degradación y explotación de la trata de personas en la Encíclica Fratelli tutti. Sin embargo, lo que es notable es cuán prioritario es este flagelo para el papa Francisco, y cuán profundamente preocupado está por la prevención y el alivio de los sufrimientos asociados. En el capítulo «Una ausencia de dignidad humana en las fronteras (An absence of human dignity on the borders)", el santo padre sostiene que, tanto en los regímenes populistas como en los neoliberales, la entrada de migrantes está bloqueada y que la ayuda a los países menos industrializados es muy escasa. Cree que esto puede conducir a los países a «tocar fondo y verse obligados a tomar medidas de austeridad» (papa Francisco, 2020, \#37). Las medidas de austeridad pueden ser tan extremas como para no respetar la vida humana, los más afectados son quienes huyen de guerras, persecuciones y catástrofes naturales. De igual forma, hace hincapié acerca de la tragedia de los sueños destrozados, de las duras realidades que enfrentan los migrantes y refugiados a manos de los traficantes:

Lamentablemente algunos se sienten atraídos por la cultura occidental, a veces con expectativas poco realistas que los exponen a graves decepciones. Traficantes sin 
escrúpulos, frecuentemente vinculados a los cárteles de la droga o de las armas, se aprovechan de la debilidad de los migrantes, quienes con demasiada frecuencia sufren violencia, trata, abuso psicológico y físico, e indecibles sufrimientos durante su trayecto (papa Francisco, 2020, \#38).

Bajo el liderazgo directo del papa, la Sección M\&R ha desempeñado un papel vital en la transformación de esta preocupación al establecer medidas concretas. Durante 2018, organizó dos consultas con líderes de la Iglesia, académicos y profesionales experimentados y organizaciones asociadas que trabajan sobre el terreno. Seis meses de consulta, escucha, discusión y planeación dieron como resultado las Orientaciones Pastorales sobre la Trata de Personas ("Orientaciones»), aprobadas por el santo padre en 2019. Las Orientaciones son para uso de las diócesis católicas, parroquias, congregaciones religiosas, escuelas y universidades; organizaciones católicas y otras de la sociedad civil, así como cualquier otro grupo que desee responder. Según se explica en el prefacio, su objetivo es promover «la comprensión, el reconocimiento, la prevención y la erradicación de la plaga de la trata de personas; la protección de las víctimas y la promoción de la recuperación de los supervivientes». El documento se centra en lo que realmente es la trata de personas (la definición), la investigación de sus causas subyacentes, la importancia de reconocer la realidad, y la dinámica de este «espantoso y malvado negocio»; propone respuestas recomendadas a la trata de personas, incluida la recuperación de supervivientes.

A lo largo de las Orientaciones, la voz del papa Francisco es notoria. Comprende referencias de sus enseñanzas y relatos de encuentros concretos con sobrevivientes de la trata, así como de sus audiencias o visitas. Su saludo a los fieles en el Ángelus del 30 de julio de 2017 es un ejemplo:

Cada año miles de hombres, mujeres y niños inocentes son víctimas de explotación laboral y abuso sexual, del tráfico de órganos, y parece que nos hemos acostumbrado tanto a ello, que lo consideramos algo normal. iEsto es deplorable, es cruel, es criminal! Deseo recordarles a todos el deber de combatir esta repugnante plaga, una forma de esclavitud moderna (papa Francisco, 2017).

Es prioritario resaltar, al igual que Schwalbenberg, Avila y Falish (2017), que la postura de la Santa Sede contra la trata de personas no es nueva. Muchas congregaciones religiosas, especialmente las de mujeres, han sido actores clave 
durante años. En la Constitución Pastoral sobre la Iglesia en el Mundo Moderno de 1965, la Iglesia condenó las prácticas fundamentales de lo que ahora denominamos trata de personas:

La esclavitud, la prostitución, la venta de mujeres y niños, y las condiciones de trabajo vergonzosas donde la gente es tratada como instrumento de ganancia en lugar de personas libres y responsables son infamias que envenenan a la sociedad humana, degradan a sus perpetradores y son una deshonra suprema para el Creador (citado en Schwalbenberg, Avila y Falish, 2017, \#10).

Lo que es innovador es la forma en que el papa Francisco ha reconocido la conexión entre la trata de personas y la migración; ha identificado la tragedia de tantos migrantes y refugiados que caen en manos de quienes se benefician de su situación desesperada. Lo que también es nuevo, es la forma en que ha presentado una estrategia holística basada en una visión clara, y ha tratado de impulsar a la Santa Sede para que sea un participante activo en los esfuerzos internacionales, pues ha buscado reunir a los fieles católicos tanto individual como colectivamente.

\section{Los más olvidados: desplazados internos y desplazados climáticos}

Desde el inicio de su pontificado, el papa Francisco ha estado animando y dando ejemplo a la Iglesia para «acompañar» a los que de una u otra forma se ven obligados a huir. Las personas más olvidadas durante su desplazamiento son aquellas que no cruzan las fronteras, sino que huyen de sus hogares por las mismas causas que los refugiados - conflicto, persecución, violación de los derechos humanos, pobreza extrema o una combinación de éstas y otras causas complejas. En la actualidad, 50.8 millones de personas son desplazados internos (IDMC, 2010), como en Siria, Colombia o la República Democrática del Congo.

Al igual que en el caso de la trata de personas, la Sección M\&R celebró consultas con líderes eclesiásticos y organizaciones asociadas con profesionales y académicos, que trabajan en el ámbito de los desplazamientos internos, hecho que desembocó en las Orientaciones pastorales sobre personas desplazadas internamente, 
publicado en 2020. En palabras del cardenal Czerny, uno de los dos subsecretarios del papa Francisco en temas migratorios, estas Orientaciones «se nutren de la riqueza del magisterio universal y local, y de la larga tradición pastoral de las acciones que la Iglesia, en diferentes partes del mundo, ha emprendido en beneficio de los habitantes de las periferias existenciales» (Czerny, 2020). Las Orientaciones están destinadas a guiar el ministerio de la Iglesia con los desplazados internos en la planificación y el compromiso práctico, en la defensa y el diálogo.

El tema de la $106^{\mathrm{a}}$ Jornada Mundial de los Migrantes y Refugiados, el 27 de septiembre de 2020, fue «Como Jesucristo, obligado a huir. Acoger, proteger, promover e integrar a los desplazados internos». Esta Jornada Mundial es un día dedicado a sensibilizar sobre la difícil situación de las personas vulnerables que se desplazan, a rezar por ellas mientras enfrentan muchos desafíos y destacar las oportunidades que ofrece la migración. En 2020, debido a los retos provocados por la pandemia en curso, el papa amplió el alcance de su mensaje para abarcar no sólo a los desplazados internos, sino a todos los que atraviesan situaciones de precariedad, abandono, marginación y rechazo como consecuencia de la covid-19.

En 2021, el papa Francisco hace un llamado internacional sobre la difícil situación de los desplazados por la crisis climática. En el momento de redactar este artículo, la Sección de M\&R está reuniendo el conocimiento y la experiencia de las iglesias locales en todo el mundo, con el objetivo de elaborar las Orientaciones Pastorales sobre la Crisis Climática y los Desplazamientos. Esta dinámica muestra cómo la Iglesia está en movimiento con los desplazados, al tratar de sacar a la luz la difícil situación de los más olvidados para buscar justicia, conciencia y empatía.

\section{Reflexiones finales}

A lo largo de su pontificado, el papa Francisco ha aprovechado su posición como líder espiritual y moral en el escenario mundial para hablar acerca de la migración y la peligrosa situación de los migrantes, los refugiados, los desplazados internos, los desplazados climáticos y las víctimas de la trata de personas. $\mathrm{Ha}$ mostrado una profunda compasión, pero ha ido más allá para desarrollar una visión radical que proporcione un enfoque alternativo, aunque complementario a la corriente principal. Ha fundado las instituciones capaces de llevar a cabo esa visión. 
En este tiempo de pandemia, el santo padre ha estado atento a no distinguir entre los importantes y los invisibles, los asentados y los desplazados: todos son vulnerables y cada contagio es un peligro para todos (Czerny, 2020). En su viaje con los migrantes parece decirnos lo mucho que las personas desplazadas nos ofrecen, como la oportunidad de descubrir partes ocultas de la humanidad y profundizar en nuestra comprensión en torno de las complejidades del mundo. Tal vez éste sea y será su legado: es a través de los migrantes y refugiados que se nos invita a encontrar a Dios, «aunque para nuestros ojos sea difícil reconocer a Dios» (papa Francisco, 2020, \#6, citando la Homilía, 15 de febrero de 2019).

La homilía que pronunció en el quinto aniversario de su visita a Lampedusa sirve como conclusión adecuada a esta reflexión sobre su liderazgo referente al aludido tópico:

Ante los desafíos de los movimientos migratorios contemporáneos, la única respuesta razonable es la de solidaridad y la misericordia. Una respuesta menos preocupada por los cálculos que por la necesidad de una distribución equitativa de responsabilidades, una valoración honesta y sincera de las alternativas y una gestión prudente. Una política justa es la que está al servicio de la persona, de todos los involucrados; una política que ofrezca soluciones que garanticen la seguridad, el respeto de los derechos y la dignidad de todos; una política preocupada por el bien del propio país, al tener en cuenta el de los demás en un mundo cada vez más interconectado (papa Francisco, 2018, \#6).

\section{Referencias}

Appleby, J.K. (2020). "Implementation of the global compact on safe, orderly and regular migration: a whole-of-society approach». Journal on Migration and Human Security, 8(2), pp. 214-229.

Baggio, F. (2017). Migrants and refugees. Challenges and opportunities: the role of the catholic church. Council of Europe 2017. Recuperado de https://migrants-refugees.va/wpcontent/uploads/2017/11/Allegato-P-Fabio.pdf

Campana, P. y Varese, F. (2015). "Exploitation in Human Trafficking and Smuggling». European Journal on Criminal Policy and Research, 22, pp. 89-105. DOI: https://doi. org/10.1007/s10610-015-9286-610.1007/s10610-015-9286-6 
International Catholic Migration Commission (ICMC) (30 de julio de 2018). "Pope Francis says it is the responsibility of all to oppose human trafficking». Recuperado de https://wWw.icmc.net/2018/07/30/pope-francis-says-it-is-the-responsibility-of-all -to-oppose-human-trafficking/

Internal Displacement Monitoring Center (IDMC) (2020). «Global Report on Internal Displacement, 2020». Recuperado de https://www.internal-displacement.org/ global-report/grid2020/

Migrants \& Refugees Section, Dicastery for Promoting Integral Human Development (2018). Twenty Action Points for the Global Compacts. Ciudad del Vaticano. Recuperado de https://migrants-refugees.va/wp-content/uploads/2019/03/20-ActionPoints-for-the-Global-Compacts.EN_.pdf

Migrants \& Refugees Section, Dicastery for Promoting Integral Human Development (2019). Pastoral Orientations on Human Trafficking. Ciudad del Vaticano. Recuperado de https://migrants-refugees.va/documents/en/email/pastoral-orientations-onhuman-trafficking.pdf

Migrants \& Refugees Section, Dicastery for Promoting Integral Human Development (2020). Pastoral Orientations on Internally Displaced People. Ciudad del Vaticano. Recuperado de https://migrants-refugees.va/wp-content/uploads/2020/05/1.-ReadOn-Screen-A5-EN-.pdf

Oficina de Naciones Unidas contra la Droga y el Delito (UNODC) (2009). Combating Trafficking in Persons - A Handbook for Parliamentarians. Ornganización de las Naciones Unidas. Recuperado de https://www.unodc.org/documents/middleeastand northafrica/human_trafficking_indicators/Handbook_for_Parliamentarians tafficking_in_persons_English_.pdf

Papa Francisco (8 de julio de 2013). «Homily at ‘Arena〉 sports camp, Salina Quarter, Lampedusa». Recuperado de http://w2.vatican.va/content/francesco/en/homilies /2013/documents/papa-francesco_20130708_omelia-lampedusa.html

Papa Francisco (2013). Evangelii Gaudium: apostolic exhortation on the proclamation of the gospel in today's world. Ciudad del Vaticano: Libreria Editrice Vaticana.

Papa Francisco (2013). Evangelii Gaudium. Exhortación apostólica del Santo Padre Francisco a los obispos, a los presbiteros y diáconos, a las personas consagradas y a los fieles laicos sobre el anuncio del evangelio en el mundo actual. Recuperado de http://wWw.vatican. $\mathrm{va} /$ content/dam/francesco/pdf/apost_exhortations/documents/papa-francesco _esortazione-ap_20131124_evangelii-gaudium_sp.pdf

Papa Francisco (10 de abril de 2014). "Address to participants in the International Conference on Combating Human Trafficking». Recuperado de http://www.vatican.va/ 
content/francesco/en/speeches/2014/april/documents/papa-francesco_20140410_ tratta-persone-umane.html

Papa Francisco (5 de agosto de 2014). "Message for the World Day of Migrants and Refugees, 2014». Recuperado de https://w2.vatican.va/content/francesco/en/messages/ migration/documents/papa-francesco_20130805_world-migrants-day.html

Papa Francisco (25 de noviembre de 2014). "Address to the European Parliament. Brussels». Recuperado de http://w2.vatican.va/content/francesco/en/speeches/2014/ november/documents/papa-francesco_20141125_strasburgo-parlamento-europeo. html

Papa Francisco (6 de septiembre de 2015). «Angelus address». Recuperado de https:// w2.vatican.va/content/francesco/en/angelus/2015/documents/papa-francesco_ angelus_20150906.html

Papa Francisco (1 de enero de 2015). "Message for the World Day of Peace: no longer slaves but brothers and sisters». Recuperado de http://www.vatican.va/content/ francesco/en/messages/peace/documents/papa-francesco_20141208_messaggioxlviii-giornata-mondiale-pace-2015.html

Papa Francisco (2015). Carta Encíclica LAUDATO Sí. Recuperado de http://www.vatican.

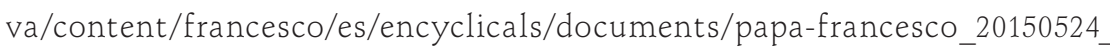
enciclica-laudato-si.html

Papa Francisco (16 de abril de 2016). «Meeting with the people of Lesvos and with the catholic community. A remembering of the victims of migration». Recuperado de http://www.vatican.va/content/francesco/en/speeches/2016/april/documents/ papa-francesco_20160416_lesvos-cittadinanza.html

Papa Francisco (3 de junio de 2016). "Cumbre internacional de jueces y magistrados contra el tráfico de personas y el crimen organizado». Ciudad del Vaticano. Recuperado de http://www.vatican.va/content/francesco/es/speeches/2016/june/ documents/papa-francesco_20160603_summit-giudici.html

Papa Francisco (21 de febrero de 2017). «Address of His Holiness Pope Francis to participants in the International Forum on "Migration and Peace». Recuperado de http://w2.vatican.va/content/francesco/en/speeches/2017/february/documents/ papa-francesco_20170221_forum-migrazioni-pace.html

Papa Francisco (3 de abril de 2017). "Greeting to the OSCE Conference». Recuperado de http://www.archivioradiovaticana.va/storico/2017/04/03/popes_message_to_ osce_human_trafficking_conference/en-1303043

Papa Francisco (30 de julio de 2017). «Angelus». Recuperado de http://www.vatican.va/ content/francesco/en/angelus/2017/documents/papa-francesco_angelus_20170730.html 
Papa Francisco (22 de septiembre de 2017). «Address to the national directors of the Pastoral Care for Migrants». Recuperado de http://www.vatican.va/content/ francesco/en/speeches/2017/september/documents/papa-francesco_20170922_ direttori-pastoralimigranti.html

Papa Francisco (2018). Encyclical Letter Gaudete et Exsultate. Recuperado de http://w2.vatican.

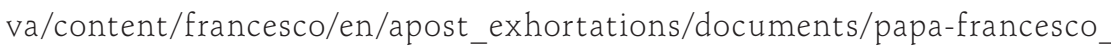
esortazione-ap_20180319_gaudete-et-exsultate.html

Papa Francisco (14 de enero de 2018). "Message of the Holy Father Francis for the World Day of Migrants and Refugees. Welcoming, protecting, promoting and integrating migrants and refugees». Recuperado de https://press.vatican.va/content/ salastampa/en/bollettino/pubblico/2017/08/21/170821a.html

Papa Francisco (21 de enero de 2018). "Message of His Holiness Pope Francis for the celebration of the 51st World Day of Peace: migrants and refugees: men and women in search of peace». Recuperado de http://w2.vatican.va/content/francesco/ en/messages/peace/documents/papa-francesco_20171113_messaggio-51giornat amondiale-pace2018.html

Papa Francisco (6 de julio de 2018). "Holy Mass for migrants: homily of His Holiness Pope Francis». Recuperado de http://www.vatican.va/content/francesco/en/ homilies/2018/documents/papa-francesco_20180706_omelia-migranti.html

Papa Francisco (29 de julio de 2018). «Angelus». Recuperado de http://www.vatican.va/ content/francesco/en/angelus/2018/documents/papa-francesco_angelus_2018 0729.html

Papa Francisco (2020). Carta Encíclica FRATELLI TUTTI del Santo Padre Francisco sobre la fraternidad y la amistad social. Recuperado de http://www.vatican.va/content/francesco/ es/encyclicals/documents/papa-francesco_20201003_enciclica-fratelli-tutti.html

Papa Francisco (13 de mayo de 2020). «Message on World Migrants Day». Recuperado de https://www.vatican.va/content/francesco/en/messages/migration/documents/ papa-francesco_20200513_world-migrants-day-2020.html

Papa Francisco (28 de julio de 2020). «Message on $106^{\text {th }}$ World Day of Migrants and Refugees 2020». Recuperado de https://www.cbcew.org.uk/message-of-his-holiness -pope-francis-for-the-106th-world-day-of-migrants-and-refugees-2020/

Rowlands, A. (2018). Catholic Teaching and Tradition: Guiding ICMC's Response to the Human Face of Migration. Roma: ICMC Council Plenary Meeting.

Schwalbenberg, H., Avila, G. y Falish, T. (2017). «Consultation on human trafficking». Recuperado de https://www.fordham.edu/download/downloads/id/11823/2017 Cassamarca_Human_Trafficking_Report.pdf 
Vatican News (23 de septiembre de 2020). "Cardinal Czerny, displaced persons can be a positive force». Recuperado de https://www.vaticannews.va/en/vatican-city/ news/2020-09/cardinal-czerny-displaced-persons-can-be-a-positive-force.html

Vatican News (9 de febrero de 2020). «Pope Francis: an economy without human trafficking is an economy of care». Recuperado de https://www.vaticannews.va/en/ pope/news/2021-02/pope-francis-human-trafficking-world-day-prayer.html 